\title{
A Description of the Theme Structure of Bai Clause
}

\author{
Suqin Li1,2 \\ ${ }^{1}$ School of Foreign Languages of Southwest University, Chongqing, China \\ ${ }^{2}$ School of Foreign Languages of Dali University, Dali, China \\ Email: li_suchin666@163.com
}

Received 15 November 2015; accepted 21 December 2015; published 24 December 2015

Copyright (C) 2015 by author and Scientific Research Publishing Inc.

This work is licensed under the Creative Commons Attribution International License (CC BY). http://creativecommons.org/licenses/by/4.0/

(c) (i) Open Access

\begin{abstract}
The Bai language (shortened as Bai) used in southwest China demonstrates a variety of typological facets in terms of the Theme structure. The usual Theme in Bai clauses is a nominal phrase, or a pronominal phrase. Bai clauses can often start with the Object being the topical Theme. It has low tolerance for multiple Themes. The subjectless clauses indicate richer possibilities in construing meaning than their counterparts with recovered Subjects.
\end{abstract}

\section{Keywords}

Bai, Types of Themes, Topical Theme Marker

\section{Introduction}

Making meaning is one of the major functions of semiotic signs. At the rank of clause, meaning is realized through the representation by words and phrases or groups, and being presented with various choices of the clausal configuration. Whether in the form of a dialogue, or a monologue, or a text of any genre, language users make meaning via choice in configuring the clause. The point from where to initiate a clause, which is called the Theme in SFL, can often suggest more than the literal meaning of the text or discourse. The linguistic unit at the clause initial place in the case of English or other languages is regarded as the THEME of the clause. Thematic system is universal in languages, but languages are diverse on the issue of Theme types, and the realizational features. In this paper, we try to display the structure and three features of the thematic system of Bai, one language in the Sino-Tibetan family used in southwest China.

\subsection{About the Bai Language and Data Source}

Bai nationality is one of the 25 officially recognized ethnic groups mainly living in Yunnan, a southwestern 
province of China. Among the 2 million people who register to government record as Bai minority, about half can speak Bai language, or shortened as Bai. The next generation of Bai who move to cities can hardly speak or understand Bai. So the language is used in a shrinking population. Being a Sino-Tibetan language spoken by Bai nationality in China, Bai demonstrates a variety of typological facets in its grammar within Systemic Functional linguistic theoretical framework. Among them, the thematic system indicates a bunch of features.

Bai so far keeps in argument among scholars as to its genetic affiliation with century-lasting competing diverse hypotheses. As the grammar of Bai is highly assimilated by Chinese and 70\% of the Bai vocabulary can be traced their source back to middle-ancient Chinese words, a competing view holds that Bai is a sister language of Chinese. The other prevailing point maintains that Bai is of Yi-Burma branch. A few scholars believe Bai should be a branch of language at the same level with Yi-Burma branch. Most of the studies on Bai languages are carried out from historical linguistic angles, specifically, at phonetic and phonological comparison or etymological levels, grammatical comparison with Chinese, with Yi-Burma languages, to look for its relationship between other Sino-Tibetan languages. In recent years, increasing typological evidences and findings from grammar studies support the second view that Bai is a language genetically belonging to Yi-Burma branch. (Zhao, 2009).

In the thematic structure analysis, a majority of the examples are cited from publication, with a few constructed by the author, a native speaker of middle dialect from Niujie, a town at the border between Eryuan county and Jianchuan county. The clauses are transcribed in International Pronunciation Alphabets (IPA), with syllable tone mark via pairs of figures like 33,44 , or 35 on the right side and lifted high as in $t e^{44}, l u^{55} \mathrm{ja}^{44}$.

\subsection{Thematic Structure in SFL}

Every clause is organized as a message-a quantum of information flowing from the author or speaker to the reader or listener as a text or discourse unfolds in its context of situation. The function of giving message or information is assumed a general role of a clause in all languages (Halliday \& Matthiessen, 2004: p. 64). In a clause, the configuration of the clause indicates the three functions-textual, interpersonal and ideational functions, with other minor functions. They map on each other, and are realized with sets of choices respectively in Transitivity system, Mood system and Theme system as the core in each function. According to SFL views about potential resources of meaning creation, Theme system indicates the author's choice of the departure point of his discourse. The remainder part after the Theme is named the Rheme following Prague school terminology. The Rheme part will tell more about the Theme, for instance, what happens to it or what it does to other participant(s) if there are some, etc.

Themes in a clause get finer classification in terms of the functions, which are subdivided as the textual, topical/experiential and/or interpersonal Themes. We take English as the background in this study. Three kinds of Themes interweave in a smooth way to develop the text. The thematic system in languages presents various features. English is positional in terms of the location of the three types of Themes coming from left to right. Themes in other language may present different features. In Bai clauses, less textual and interpersonal Themes precede topical Themes, and topical themes are mostly marked when the topical Themes are the Objects.

\section{Types of Themes in Bai Clauses}

Before we dig into the linguistic data and carry out the systemic and functional analysis, a brief introduction to the options of Themes in Bai in SFG will be necessary. Here we present clause analysis of several Bai clauses excerpted from the ballad Huangshinu Answering Diamond Sutra (Duan, 2011).

E.g. 2-1

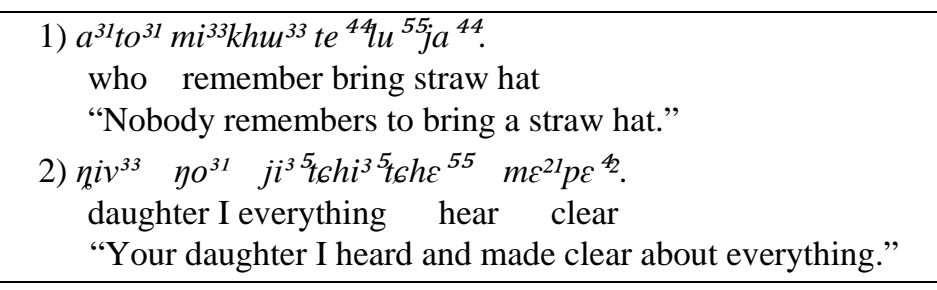




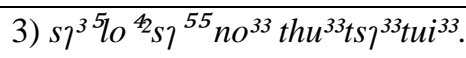

Shilong Temple's way is far.

"The way to Shilong Temple is far."

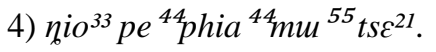

Need walk till that late

"You need walk a long time."

5) $\eta u^{44} \mathrm{tu}^{21} \mathrm{ko}^{55} \mathrm{thi}^{33} \quad \mathrm{ts}^{55} \mathrm{ui}^{55} \mathrm{ju}^{44}$.

late lunch with younger brother let heat eat

"Your late lunch with your younger brother warm and eat."

6) $\mathrm{mia}^{44} \mathrm{tu}^{44} \quad \mathrm{vv}^{33} \quad \mathrm{ka}^{35} \quad \mathrm{kho}^{33}$.

get wet rain several drops

"(I) get wet in several drops of rain."

Themes are expressed by an interrogative $a^{31}$-word (equivalent to WH-word in English), for instance, $a^{31} t 0^{31}$ (2-1-1), or a noun or a nominal phrase $\eta i^{33}$ with an apposition pronoun $\eta o^{31}(2-1-2)$, or a circumstance

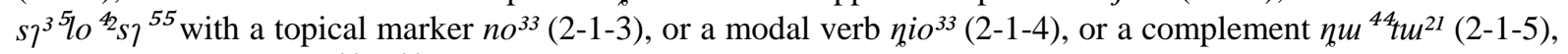
or a verbal-phrase $\mathrm{mia}^{44} \mathrm{tm}^{44}(2-1-6)$ respectively. The first feature of Bai Theme is that most of linguistic units, particularly, the participants, the process and the circumstantial elements can function as the Theme, and the feature is common. Bai language demonstrates language-featured Theme choice, such as objects' being the Theme for preposition of the prominence. We will exemplify the features below.

\subsection{Thematic Potential and Analysis in Bai}

Bai shares similarities with Chinese in terms of its grammar, as it has continuous contact with Chinese in depth early from Qin and Han dynasty (221BC-220AD). The impressive two-layer thematic analysis for Chinese long clause is to recognize differing degrees of thematicity, and include all experiential elements within the Theme up to the Process, or the minor Process represented by the coverb of a coverbal phrase (Cafferal, Martin, \& Matthiessen, 2004). By this principle of theme identifying, everything up to the Process would have some degree of Thematic potential, with the initial group having the greatest. To illustrate the point, we cited the analysis example on Chinese by Halliday and McDonald (Halliday \& McDonald, 2004: pp. 321, 322) and then translate it into its Bai equivalent and testify the applicability of the second principle of Theme identifying in Bai. For instance:

E.g. 2-2

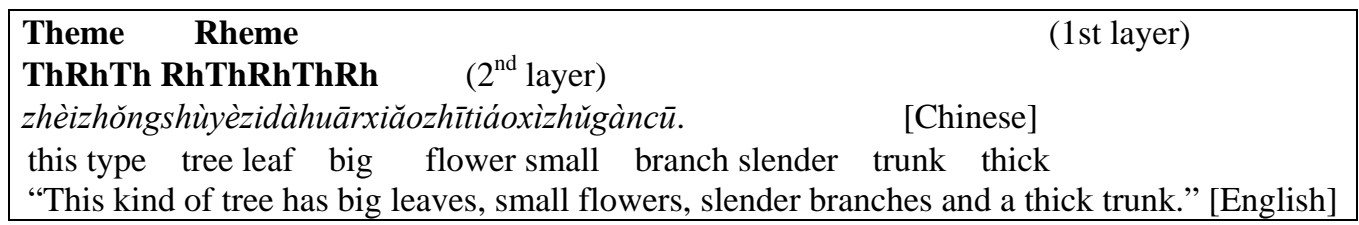

Being translated into English, the clause lost the second layer of theme-rheme structures. But in Bai equivalent version below, the two layers of theme-rheme structures remain quiet the same with that in Chinese.

E.g. 2-3 Bai version (translated from the Chinese clause in Example 2-2)

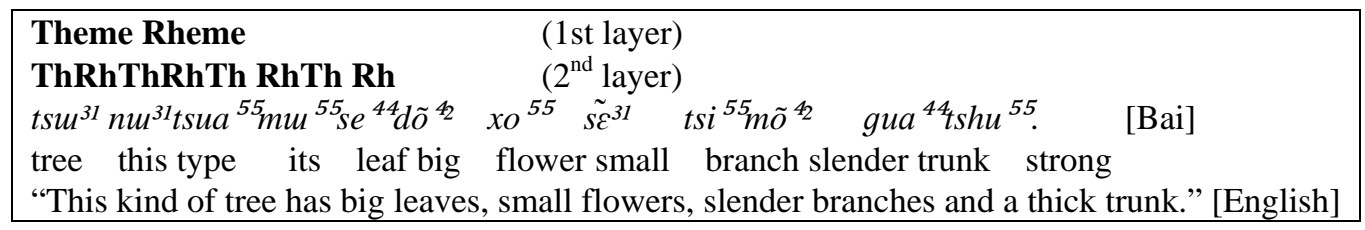

According to Halliday's suggestion, in the first layer analysis, the Theme zhèi zhŏng shù/tsum ${ }^{31} n u^{31} t_{s u a}{ }^{55}$ "this type of tree" has the greatest degree of thematic potential. The minor processes have less thematic potential. 
At the second layer analysis, there are four minor clauses, in which the degrees of thematicity diminish gradually. When we compare the two thematic analyses in the two languages we believe that the two-layer analysis is suitable for Bai clauses. We accept this analysis as the better way of identifying Theme-Rheme in Bai language.

\subsection{Three Themes}

To get a general view of the thematic structure in Bai, in Graph 1 we analyze excerption from a fable we $e^{55}$ $a^{55} \mathrm{SE}^{31} \mathrm{no}^{33} \mathrm{pe}^{21} \mathrm{tsi}{ }^{55} \mathrm{fv}^{55} \mathrm{mu}^{55} \mathrm{pe}^{21}$ "Why should people skin the palm tree off its frond?" (Zhang \& Zhou, 2013).

Graph 1. Theme options in the Palm and Pine fable (Para.1-3).

\begin{tabular}{|c|c|c|c|}
\hline Textual & Interpersonal & Marked topical & Unmarked topical \\
\hline 1. & & $d u^{21} m a^{44} x u^{31}$ "long time ago" & \\
\hline 2. & & & $m a^{55} k \tilde{o}^{33} t s u^{31}$ "they two" \\
\hline 3. & & & phia ${ }^{44}$ t6hi ${ }^{44}$ pia $^{44}$ yua ${ }^{44}$ "in July and Autumn" \\
\hline 4. & & & $6 i \tilde{o}^{21} t s u^{31}$ “pine tree” \\
\hline 5. & & tvn ${ }^{55}$ yua 44 “winter” & \\
\hline 6. & & & $m o^{31}=$ ciõ $^{21}$ tsur $^{31}$ "pine tree" \\
\hline 7. & $l a^{35}$ “So" & $t s i^{55} f^{55} t s u^{31}$ "palm tree” & \\
\hline 8. & & & $\left(m o^{31}=t s i^{55} f v^{55} t s u^{31}\right)$ "he = palm tree" \\
\hline 9. & $a^{31} f v^{55} t_{6 i a^{4}}$ & $x \tilde{a}^{31} t s i^{33}$ sua ${ }^{44 ،}$ every year” & \\
\hline 10. & & & $y o^{31}=t s i^{55} \mathrm{fv}^{55} \mathrm{tsu}^{31}$ “I $=$ palm tree" \\
\hline 11. & $m u^{55} x u^{31 “ a}$ among which” & & \\
\hline 12. & & & $x \tilde{e}^{55 \text { "the sky" }}$ \\
\hline 13. & & & 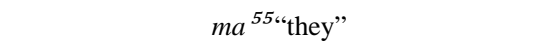 \\
\hline 14. & & $t s u^{33}$ "have" & \\
\hline 15. & & & $\epsilon_{i} \tilde{o}^{21} t s u^{31}$ “pine” \\
\hline 16. & $a^{31} f^{55}$ t6hia ${ }^{42}$ “"my best friend” & & $n o^{31}=t s i^{55} f v^{55} t s u^{31}$ “you = palm” \\
\hline 17. & & & $6 u i^{33}$ "water" \\
\hline 18. & & & $j \tilde{a}^{55}=\mathrm{cio}^{21} \mathrm{tsu}^{31}+\mathrm{tsi}^{55} \mathrm{fv}^{55} \mathrm{tsu}^{31}$ “we” \\
\hline 19. & & & $y o^{31}=6 i \tilde{o}^{21} \mathrm{tsu}^{31}$ “pine” \\
\hline 20. & & & $6 u i i^{33}$ "water" \\
\hline 21. & & & $t h u^{33} \mathrm{si}^{33}$ "soil” \\
\hline 22. & $r a^{3}{ }^{5} \mathrm{xo}^{55} \mathrm{tsi}^{55}$ “otherwise” & & $j \tilde{a}^{55}={ }_{6 i} \tilde{o}^{21} t s u^{31}+t s i^{55} f v^{55} t s u^{31}$ \\
\hline 23. & $l a^{3} 5$ “then” & & $\left(j \tilde{a}^{55}\right)=6 i \tilde{o}^{21} t s u^{31}+t s i^{55} f v^{55} t s u^{31}$ \\
\hline 24. & & & $t s i^{55} f v^{55} t s u^{31}$ \\
\hline 25. & 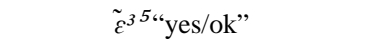 & & $6 i \tilde{o}^{21} t s u^{31}$ "pine” \\
\hline 26. & & $p e^{44} t u^{21} \eta v^{55}$ "before leaving" & \\
\hline 27. & & & $n o^{31}=t s i^{55} \mathrm{fv}^{55} t s u^{31}$ \\
\hline 28. & & & $t s i^{55} f v^{55} t s u^{31}$ \\
\hline 29. & $a^{31} \mathrm{fv}^{55}$ tchia $^{4_{2}}$ & $a^{31}$ mia $^{44 \text { “don’t” }}$ & \\
\hline 30.31. & & & $\eta o^{31}=t s i^{55} f v^{55} t s u^{31}$ \\
\hline 32. & & & $j \tilde{a}^{55}=t s i^{55} f v^{55} t s u^{31}+6 i \tilde{o}^{21} t s u^{31}$ "we” \\
\hline 33. & jö $\tilde{o}^{33} \mathrm{sua}^{44}$ “if” & & $\eta o^{31}=t s i^{55} f v^{55} t s u^{31}$ \\
\hline 34. & & & $n o^{31}=6 i \tilde{o}^{21} t s u^{31}$ \\
\hline
\end{tabular}


Table 1. Topical Theme markers.

\begin{tabular}{|c|c|c|}
\hline markers & Meaning & Examples \\
\hline$t s i^{55}$ & $\begin{array}{l}\text { Marker after nouns, or subclause, to } \\
\text { indicate a condition or a comparison. }\end{array}$ & 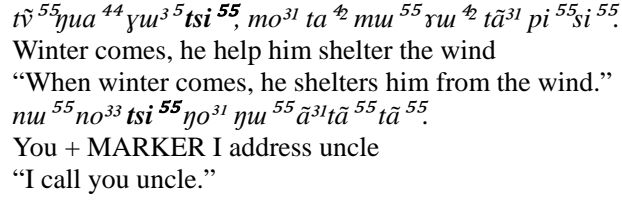 \\
\hline$n o^{33}$ & $\begin{array}{l}\text { Marker after personal pronouns, } \\
\text { nominal phrase, to foreground the } \\
\text { complement }\end{array}$ & $\begin{array}{l}n u^{55} \text { no }^{33} \eta o^{31} \eta u^{55} a^{55} S \varepsilon^{21} ? \\
\text { you + MARKER I call what } \\
\text { "How should I address you?" } \\
n e^{21} \mathrm{ku}^{31} \text { thi }^{55} \text { no }^{33} \mathrm{xu}{ }^{55} \mathrm{a}^{31} \text { tho } \\
\text { staircase + MARKER (I) step will not } \\
\text { "I will not step on the staircases.” }\end{array}$ \\
\hline$y v^{55}$ & $\begin{array}{l}\text { Marker after personal pronouns, to } \\
\text { foreground the complement }\end{array}$ & $\begin{array}{l}n u^{55} \eta v^{55} \eta o^{31} \eta u^{55} a^{55} \varepsilon^{21} ? \\
\text { you + MARKER I call what } \\
\text { "How should I address you?" }\end{array}$ \\
\hline
\end{tabular}

3) Adjuncts (11 times), e.g. $m u^{55} x u^{31}$, “among which”, $p e^{44} t u^{21} y v^{55}$ "before leaving”, etc.

4) Predicators (6 times), e.g. tsum ${ }^{33}$ "have”, $k o^{42} t^{33}$ "live” etc.

\subsection{Marked and Unmarked Themes}

When the Subject serves as the Theme, it is unmarked. But in most cases, to cater to a certain need of meaning expression, a speaker or writer tends to choose other grammatical part as the starting point of a clause. Other grammatical elements, such as circumstance, complement, and adjunct will be selected as the Theme, which is a Marked Theme. In the 54 clauses in the fable story, 17 Themes are marked topical Themes, and 39 Themes are unmarked topical Themes. The proportion can be understood that marked topical Themes amount to a considerable percentage.

Here are more clauses with marked Themes. Examples 2-5 (1-8) are clauses from a monologue from the longest Bai Ballad Huangshinu Answering the Diamond Sutra (Duan, 2011).

E.g. 2-5

\begin{tabular}{|c|}
\hline 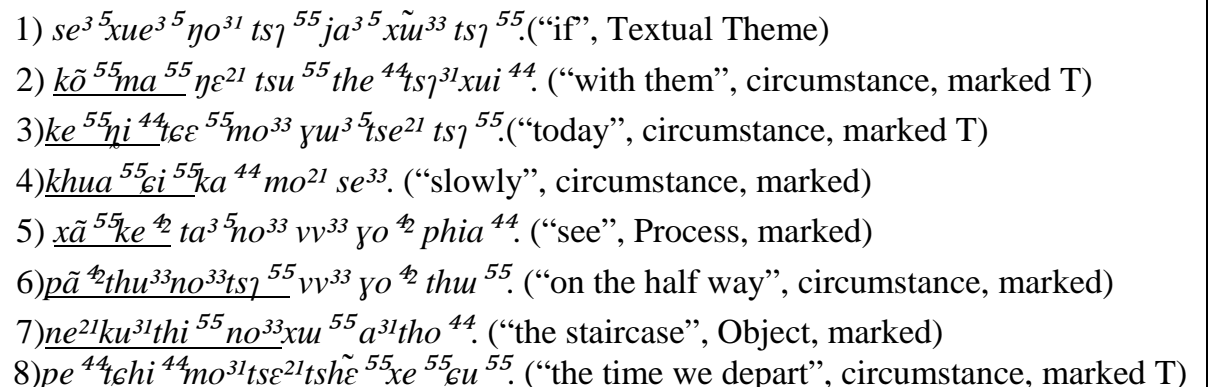 \\
\hline
\end{tabular}

So far two major features might be safely summed up. The first feature is that in most of the declarative clauses it is the process which initiates the clauses when the understood Subject is yo $^{31}$, or $\eta$ na $^{55}$ "inclusive we". In imperative clauses, with elliptic no ${ }^{31}$ "sgl. you” and $n a^{55}$ “pl. you”, the situation is quite alike with that in English and Chinese, in which the process serve as the marked Theme.

E.g. 2-6
a) $\mathrm{mia}^{44} \mathrm{tu}^{44} v v^{33} \mathrm{ka}^{4_{2}} \mathrm{kho}^{33}$. ("get wet in the rain", process, marked)
b) tchi $^{44} \mathrm{phia}^{44} \mathrm{u}^{55} \mathrm{mi \varepsilon}^{42} \mathrm{no}^{33}$. ("feel sad”, process, marked)
c) $\underline{t_{6} a^{44}} \mathrm{pi}^{55} \eta_{6 i}{ }^{55} \mathrm{jo}^{44} \mathrm{t}_{6} \mathrm{ha}{ }^{44}$. ("ask for", process, marked)

The second feature is that the Object can often be shifted to the initial location, that is, to the position of 
Theme in those clauses which have two or more participants, and most of the time marked by the auxiliary no ${ }^{33}$. For instance:

E.g. 2-7

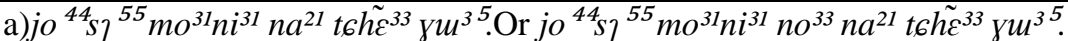

$$
\begin{aligned}
& \text { ("doctor that", Object pre-positioned to be marked Theme) }
\end{aligned}
$$

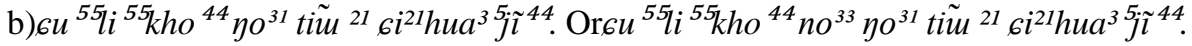

$$
\begin{aligned}
& \text { ("pear one”, meaning “pear (one) I really like to eat.”). }
\end{aligned}
$$

As to the marked topical Themes, scholars have found some languages in which the users can represent Themes via topical markers, as in Japanese the particle - wa (Hu, 1992; Teruya, 2004), the ang phrase in Taga$\log$ (Martin, 2004). Bai scholars sum up some topical markers in Middle and South dialects of Bai with topical markers, such as $t s i{ }^{55}, l^{55},{ }^{33}$ (Wang \& Wang, 2013; Zhao, 2013).

Revisiting the tale analyzed, we notice that a group of particle words such as $t s i^{55}$ and $l i{ }^{55}$ are applied after the marked Themes. Here are some words which mark the Themes in Table 1. The part which is located before these markers often functions as the topical Theme.

In terms of function, $t \mathrm{si}^{55}$ is a topical marker used after nouns or subclauses to indicate a condition or a comparison. In the clause $t \tilde{v}{ }^{55} \mathrm{yua}^{44} \mathrm{\gamma u}^{35} \mathrm{tsi}^{55}, \mathrm{mo}^{31} \mathrm{ta}^{42} \mathrm{~mm}^{55} \mathrm{rm}^{42} \mathrm{ta}^{31} \mathrm{pi}^{55} \mathrm{Si}^{55}$, before the clause phia ${ }^{44} \mathrm{tchi}^{44}$

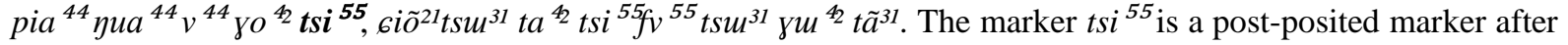
the topical Themes. Here are two topical Themes indicating that the palm tree always takes after the pine tree.

The function of $n 0^{33}$ is to mark the Theme, particularly when the Theme is played by the Object of clause. We illustrate the point with a clause excerpted from Huangshinu Answering the Diamond Sutra. E.g. $\mathrm{S}^{3}{ }^{5} \mathrm{O}^{4} \mathrm{~S}^{55}$ $n o^{33} t^{2} u^{33}{ }^{3} 7^{33} t u i i^{33}$ (to Shilong Temple, PREP-phrase, $n o^{33}$, topical Theme marker, circumstance element as Theme) meaning "it is a long way to Shilong Temple's." In the clause, the part which is marked by no ${ }^{33}$ is actually a nominal phrase functioning as location to mean "the way to Shilong Temple".

With the help of the topical Theme marker $n 0^{33}$, the second singular possessive pronoun nu ${ }^{55}$ can be used as the foregrounded complement to enjoy the prominence and to become the focus. Compare the two clauses and we may observe the minute touch of meaning contrast in example 2-8:

E.g. 2-8

1) $n u^{55} y v^{55} \eta o^{31} \eta u^{55} a^{55} \varepsilon^{21}$ ? "You, what should I address?"

2) $\mathrm{mu}{ }^{55} \mathrm{no}^{33} \mathrm{tsi}^{55} \mathrm{yo}^{31} \eta \mathrm{u}^{55} \tilde{a}^{31} t \tilde{a}^{55} \mathrm{a}^{55}$. "As to him, I call uncle."

In the first clause, the marker $y v^{55}$ makes the personal pronoun $n w^{55}$ a Theme. The second clause contains two Theme markers $n o^{33}$ and $t s i^{55}$. $n o^{33}$ is put after the personal pronoun $m u^{55}$ ("he") to make it a Theme. $t s i^{55}$ is another Theme marker to indicate a weak meaning of contrast.

Due to the choice of a writer or a speaker for certain purpose of meaning making, a majority of Bai clauses could be arranged in OV order. According to scholars in Yi-Burma study and in typology, OV is a common order in Yi-Burma language family, with a few exceptions, for example, a majority of Chinese and a small portion of Bai clauses (Li, 2013). In OV, the object serves as the Theme, which is different from the normal order of declarative clauses.

\subsection{Themes in Clause Complexes in Bai}

Bai clauses could be combined in two ways-paratactic clause and hypotactic clause.

E.g. 2-9

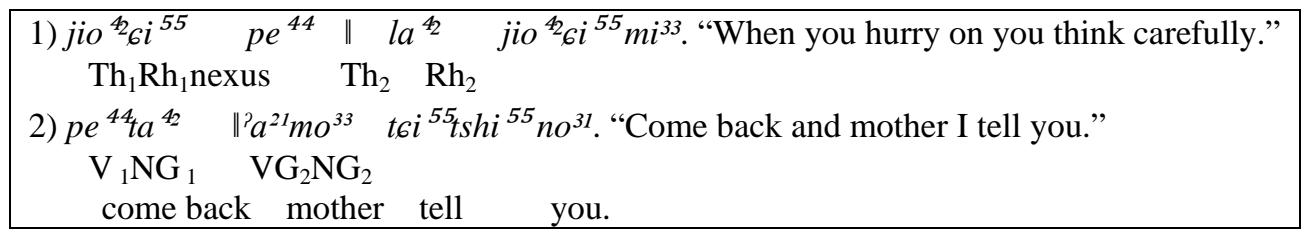


In Example 2-9 (1) a conjunction $\mathrm{la}^{4}$ is used as the nexus to link the two sub-clauses. In Example 2-9 (2), the

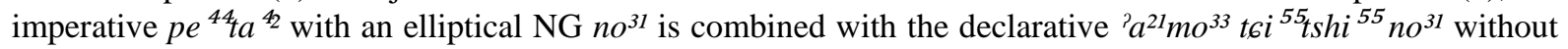
obvious nexus. A paratactic relation is observed between them.

The following examples present more features.

$\begin{array}{cc}\text { 3) } x \tilde{e}^{55} \mathrm{ka}^{55}{ }_{6 u i^{33}} & \mathrm{ra}^{3} \mathrm{mo}^{33} \text { " "It is dry and water is inadequate." } \\ \mathrm{NG}_{1} \mathrm{VG}_{1}(\mathrm{HCON}) \mathrm{NG}_{2} \quad \mathrm{VG}_{2} \\ \text { sky dry } & \text { water not no }\end{array}$

In clause 3), no explicit link word is found between the two sub-clauses. The two actions or Processes are combined in a seemingly paratactic relation. Still, at semantic expression layer, native speakers understand that there is a cause-effect hypotactic relation between the two actions or events. Because $x \tilde{e}^{55} k \tilde{a}^{55}$ "the sky is dry" (meaning the amount of rainfall is inadequate), $6 u i^{33} \mathrm{ra}^{35} \mathrm{mo}^{33}$ "there is no water" (note: here $\mathrm{ra}^{35} \mathrm{mo}^{33} \mathrm{see}^{3}$ mingly double negation, but meaning negation rather than positive. $\gamma a^{35}$ is put before verbs in polarity).

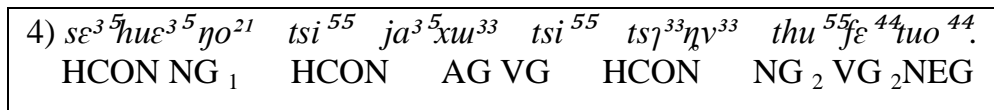

Clause (4) illustrates the marked hypotactic ordering of a hypotactic clause nexus with overt conjunction $t s i^{55}$. More examples are given to demonstrate another feature of Bai clause complex below.
5) $\eta o^{31} \quad \eta \varepsilon^{21} t u^{55} \tilde{a}^{33} t u^{44} \mathrm{kv}^{42} t s h v^{31} t s i^{55} \eta o^{31} t s h u^{33} j a^{44} \mathrm{~km}{ }^{55} u^{55} \mathrm{nu}^{55} \eta v^{55}$.

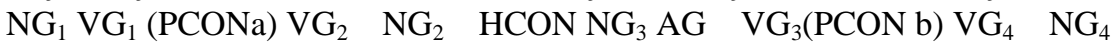
"I go down to look for a nice place and then I immediately come back to fetch you."

In clause 5), Paratactic (a) and Paratactic (b) are implicit with no conjunctions to mark them. The explicit Hypotactic relation is marked by the particle $t s i{ }^{55}$. The Verbal Group 1 and Verbal Group 2 make one serial verb construction, and the Verbal Group 3 and Group 4 make the second serial verb construction in the clause complex. The situation is quite similar to that in Chinese. Therefore the analysis is made in the model of Halliday for Chinese clause complexes and the naming "serial verb construction” is borrowed from him. We cite one Chinese clause complex example here (Halliday \& McDonald, 2004): 314.

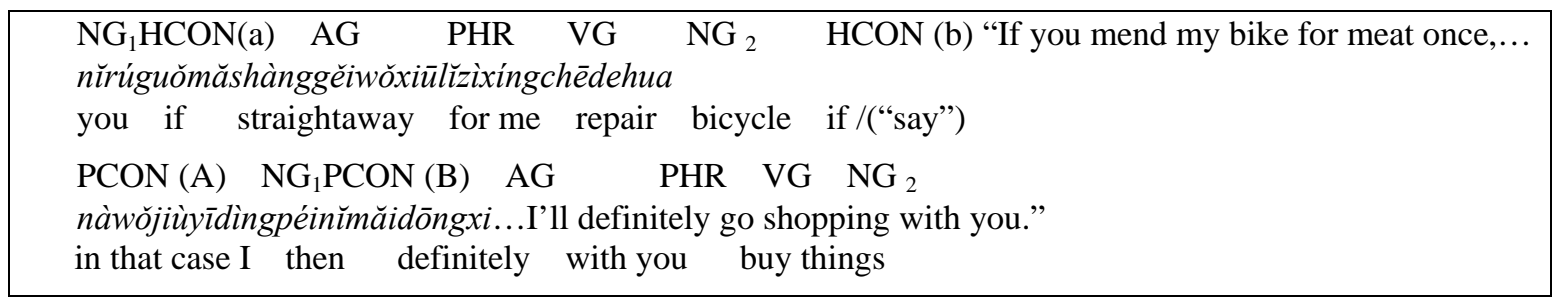

In this complex, gěi wǒ and péi ň̆ are prepositional phrases to refer to the receiver of the action. In Bai, similar constructions are frequent. See the words in bold print below:

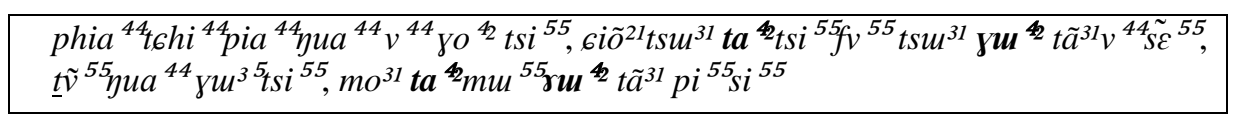

The Prepositional phrase could be a non-continuous construction as $\mathrm{ta}^{4_{2}}+\mathrm{NG}+\mathrm{gm}^{42}, \mathrm{ta}^{44}+\mathrm{NG} / \mathrm{PG}+\mathrm{no}$. Animate nominal groups or possessive personal pronouns can be inserted into the construction, such as in the interrogative $\mathrm{ta}^{44} \mathrm{yu}^{55} \mathrm{no}^{33} \mathrm{pe}^{44} \mathrm{ja}^{44}$ ? "Will you go with me?"

The last note to make is about the function of the nexus $t s i^{55}$. Contrast the following two clauses. 


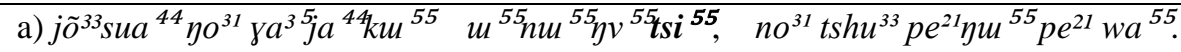
"If I do not come back to fetch you then, you can skin me off my frond."

b) $\eta o^{31} \eta \varepsilon^{21} t u^{55} \tilde{a}^{33} t u^{44} \quad v^{42} t s h v^{31} t_{s i}{ }^{55} \eta o^{31} t s h u^{33} \mathrm{ja}^{44} \mathrm{~km}{ }^{55} \mathrm{u}^{55} \mathrm{nu}^{55} \mathrm{yv}^{55}$. "I go down to look for a nice place and then I immediately come back to fetch you."

The two clauses have one difference in that the second clause has no comma after the marker $t s i^{55}$. In speaking, when there is no comma, a brief pause after the marker is discernible, whether it is after a nominal phrase, a pronoun or a dependent clause. The pause after $t s i^{55}$ in a dependent clause is longer than that after $t s i^{55}$ in a phrase or a single word.

Bai language has been found to be a Topic-prior language. "Topic-prior" means the topic of a clause is almost always put at the prior place, or the initial place in a clause. In Bai clauses, the situation is more likely that most of the parts of the clause can be chosen as the Theme for purpose of meaning expression and emphasis. Almost any content of the rest part could be chosen by the speaker or writer, except for the auxiliary markers like genitive case marker $n o^{33}$, modal auxiliary marker $l a^{4_{2}}$, negation adverb $m u^{33}$.

\section{Features Specific to Bai Thematic System}

Possible word orders in Bai are SVO, SOV and OSV as in Example 3-1 below.

E.g. 3-1

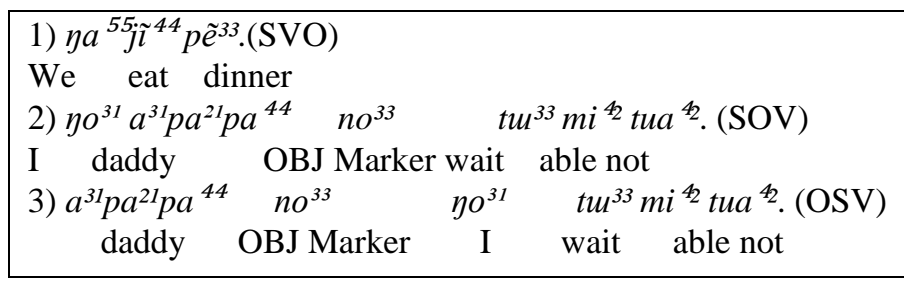

Among the three orders, SVO is dominant in most types of Mood. In SVO order the theme option and realization are similar to that in Chinese. In the two latter orders, Objects serve the function of the experiential Theme if there is no other experiential component before the Object. In addition, Example 3-1-2 and 3-1-3 show that SOV and OSV can switch to each other for certain functions such as emphasis or contrast. When it becomes an OSV order, the Object often functions as the Theme.

\subsection{Objects Being Themes in OSV Order}

Bai clauses are mainly in SVO order like in Chinese, but there appear to have certain percentage of SOV and OSV when necessary. When the personal pronominal phrase or people names are Objects in clauses, they can be shifted to precede the verbal phrase, or the Process and then produce SOV. The two clauses are taken from Baiyu Jianzhi (Xu \& Zhao, 1984: p. 77).

E.g. 3-2

1) $a^{31} n e^{44}$ suã ${ }^{44} x^{44} \quad \mathrm{no}^{33} \quad l i^{44} \mathrm{ko}^{21} \mathrm{lu}^{33}$.

Grandma grandchildren OBJ Marker too spoil

And when the Object is the prominence to stress, it moves before the Subject to create OSV order for prominence. In such case, the Object serves the marked topical Theme with the help of a marker $n o^{33}$.

\begin{tabular}{|c|c|c|}
\hline $\begin{array}{l}\text { suã }{ }^{44} x O^{44} \\
\text { andchildren }\end{array}$ & $\begin{array}{c}n o^{33} \\
\text { OBJ Marker }\end{array}$ & $\begin{array}{c}a^{31} n e^{44} \quad l i^{4} \\
\text { Grandma to }\end{array}$ \\
\hline
\end{tabular}

The particle $n 0^{33}$ cannot stand alone in making meaning. It serves as a suffix functioning and appearing after pronominal phrase or nominal phrase, or people names to mark their Object status. 


\subsection{Widening of Subject Options in Subjectless Clauses}

In some cases, the Subjects of imperatives, declaratives and interrogatives can be omitted, which result in a widening range of the possible choice of Subjects if not recovered. For instance:

E.g. 3-3

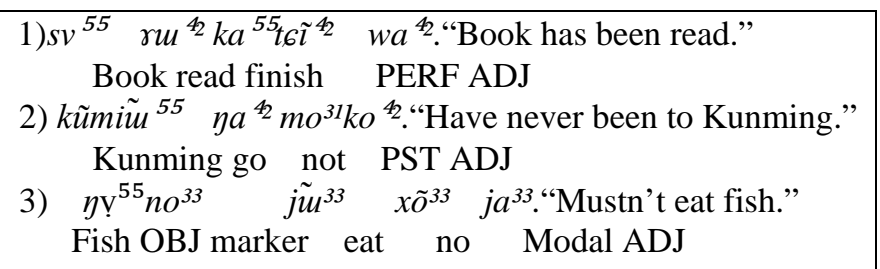

In the three seemingly Subjectless clauses above, the Themes are kümiü ${ }^{55}, s v^{55}, \eta v^{55} n 0^{33}$ respectively. They are either Objects $s v^{55}, y y^{55} n o^{33}$ with or without marker, or the Circumstance of location kümiü ${ }^{55}$. The Subject is recoverable. When the context is not given for readers, there are several possibilities of the Subject before being given with it. Once the Subject is recovered, the addressee is explicit and specified. This is probably a language universal feature. As a general rule, the Subjects in passive voice can be omitted.

E.g. 3-4

$m u^{55} \mathrm{no}^{33} \quad \mathrm{sua}^{44} \mathrm{rau}^{31}$ tuo ${ }^{42}$."Her/him, no one can win in argument.”
Her/HimOBJ-marker argue against not.

In this case, the clause is in OV order. The omitted Subject is infinite, making a claim a general judgment to assert that the man or woman is so eloquent that NOBODY could win him or her. Therefore, when the Theme is played by the Object, the omitted Subject is widened in terms of possible choice. It could be the addresser himself, or the third person not present, or anybody else. Once we switch the order to SOV $\mathrm{no}^{31} \mathrm{mu}^{55} \mathrm{no}^{33} \mathrm{sua}^{44}$ $\mathrm{rau}^{31} \mathrm{tuo}^{4_{2}}$, or to SVO $\mathrm{go}^{31} \mathrm{sua}^{44} \mathrm{rau}^{31} \mathrm{mu}^{55} \mathrm{nO}^{33} \mathrm{tuo}^{4_{2}}$, for instance. Or we simply fill in the blank for the Subject in its place in OSV order, e.g. $\mathrm{mu}^{55} \mathrm{no}^{33}$ __ sua ${ }^{44} \mathrm{rau}^{31} \mathrm{tuo}^{{ }_{2}}$, the possible choices are several, as tabulated below.

Any phrase in the table can be chosen to fill the blank in the clause $\mathrm{mu}^{55} \mathrm{no}^{33}$ sua ${ }^{44} \mathrm{rau}^{31} \mathrm{tuo}^{42}$. Once fulfilled, the Subject becoming recovered, the meaning of the clause would be confined and it reduces the force of the claim in this case.

\subsection{Low Tolerance for Multiple Themes}

Clauses in Bai begin with or without textual Theme, with or without interpersonal Theme, but they must have topical Themes. The topical themes could be the Subject, the Object, the Process, or the circumstantial element. But the frequency of co-occurrence of the three kinds of Themes is quite low here. It is the same with other kinds of texts in Bai. Compared with English, Bai language is not rich in multiple Themes. Halliday comments that there are a group of languages with low tolerance for multiple Themes. Bai could be one of this kind.

\section{Conclusion}

The description of the thematic system of Bai indicates that Bai clauses are often started with the object being the topical theme. Bai clauses have low tolerance for multiple themes and the subjectless clauses indicate richer meanings than their counterparts with recovered Subjects as the recovering would confine the actor and narrow the meaning.

\section{Acknowledgements}

This research is sponsored by Ministry of Education of the People's Republic of China, Youth research project (13YJC740046). 


\section{References}

Cafferal, A., Martin, J. R., \& Matthiessen, C. M. I. M. (2004). Language Typology: A Functional Perspective. Amsterdam/ Philadelphia: John Benjamins. http://dx.doi.org/10.1075/cilt.253

Duan, L. (2011). Huangshinu Answering the Diamond Sutra. In X. L. Zhang, Jiapei, S., Duan, L., \& M. Zhao (Eds.), The Interpretation of Bai Literature Works of China Bai Nationality (Zhongguo Baizu Baiwen Wenxian Shidu) (pp. 101-204). Guilin: Guangxi Normal University Press.

Halliday, M. A. K., \& Matthiessen, C. (2004). An Introduction to Functional Grammar (3 ed.). London/Beijing: Edward Arnold/Foreign Language Teaching and Research Press.

Halliday, M. A. K., \& McDonald, E. (2004). Metafunctional Profile of the Grammar of Chinese. In A. Cafferal, J. R. Martin, \& C. M. I. M. Matthiessen (Eds.), Language Typology: A Functional Perspective (pp. 305-396). Amsterdam/Philadelphia: John Benjamins. http://dx.doi.org/10.1075/cilt.253.08hal

Hu, Z. L. (1992). Problems Concerning Theme in Japanese Clause. Foreign Languages, 1-7, 80.

Li, Y. B. (2013). On the Universal Features of Word order between Bai and Tibeto-Burma Languages. In W. Feng, \& W. Shuangcheng (Eds.), The Article Selection of Bai Linguisitic Studyies (pp. 64-107). Shanghai: Zhongxi Press.

Martin, J. R. (2004). Metafunctional Profile of the Grammar of Tagalog. In A. Cafferal, J. R. Martin, \& C. M. I. M. Matthiessen (Eds.), Language Typology: A Functional Perspective (pp. 255). Amsterdam/Philadelphia: John Benjamins. http://dx.doi.org/10.1075/cilt.253.07mar

Teruya, K. (2004). Metafunctional Profile of the Grammar of Japanese. In A. Caffarel, J.R. Martin, \& C. M. I. M. Matthiessen (Eds.), Language Typology: A Functional Perspective (p. 185). Amsterdam/Philadelphia: John Benjamins. http://dx.doi.org/10.1075/cilt.253.06ter

Wang, F., \& Wang, S. C. (Eds.). (2013). Baiyu Yanjiu Lunwenji (Essay Collection of Studies on Bai). Zhongxi Book Company.

Xu, L., \& Zhao, Y. S. (1984). Baiyu Jianzhi (A Profile of the Bai Language). Beijing: Minzu Press.

Zhang, X., \& Zhou, Y. Z. (2013). Bai Folklores (Z. Y. Zhang, Trans.). Kunming: Yunnan Minzu Press.

Zhao, L. X. (2009). A Brief Introduction to the Language Family Category of Bai Language. Journal of Minzu University of China (Philosophy and Social Sciences Edition), 114-120.

Zhao, Y. Z. (2013). On the Bai Topical-Marker and Their Pragmatic Functions. Journal of Minzu University of China (Philosophy and Social Sciences Edition), 129-134. 